\title{
ANALYSIS OF THE PHYSICAL SPACE OF HIGHER EDUCATION WITH AN EMPHASIS ON SOCIAL AND CULTURAL FACTORS
}

\author{
Maryam Ebrahimi \\ Master at art research, Islamic Azad University, Yazd branch, Yazd, Iran.
}

\begin{abstract}
Educational environment as one of the most important urban spaces should be taken into consideration. Obviously, architectural features of educational units are considered an important factor affecting the success of the educational structure. This study analyzed the space of higher education with an emphasis on cultural and social factors. Research methodology is dealing with the problem and field study. In other words, this research is an applied research and it is the kind of descriptive and analytical. The study population included students in different courses at Iranian governmental universities and professors and experts in these centers. Research findings showed that independent variables such as naturalism, amount of spatial coherence and the availability of space were studied with the dependent variable of attitude towards improve educational quality. Naturalism and spatial coherence variables compared to other variables had the highest correlation with the improvement of educational quality. Moreover, it became clear that there is a conflict between the status quo of physical spaces in universities and cultural perspectives and performance of the students. Furthermore, according to the results obtained from professors and experts, we can say that policymaking at the macro level in relation to the cultural policy based on cultural principles and culture of students, compliance of spaces in universities with traditional and modern culture, creating spaces with Iranian and Islamic identity and create spaces for security, safety and welfare of students are the most influential ideas on improving physical space in order to improve students' cultural and social issues.
\end{abstract}

Keywords: physical space, educational environment, Identity, creating balance

\section{INTRODUCTION}

Since the 1960s, there was widespread criticism toward modern designs. The critics believed that these plans are effective on the cultural, social, traditions and historical factors and climate issues. The contrast between modern architecture and social processes and spatial behavior within it causes ordinary people and consumers change plans in order to meet the space needs. And the needs that the original designer has not paid attention to them, therefore this kind of spatial interventions were carried out regardless of the plan proposed by the designer. Thus, in the early '70s, the contextualism was brought into architecture in which the design was performed according to the existing historical and social structures and in cultural and human context (Qobadian, 2005: 240). "Estimating the social consequences of the process of analyzing (predicting, estimating and rethinking) and managing unintended and intended consequences of planned interventions (policies, programs, plans and projects) for the human environment and any process of social change is the result of these interventions, so as to create a more fair and sustainable physical and human environment»(Venclay, 2002: 387). Despite the passage of more than four decades of these global developments, observations and studies in our country have shown that terms and physical dimensions should be more considered in designing and manufacturing different areas, especially the educational facilities that are necessary to prepare the next generation. Few studies conducted, have failed to provide an appropriate space to be able to respond to all requirements.

With the arrival of students to the university environment, individuals are faced with new experiences. On the one hand, with the formation of social Identity and changes in personal identification, this educational level has become a transitional stage which needs a special attention. University environment provides different experiences, which draws the attention of students to the identity and 
forcing them to think about alternative solutions related to identity. Since a person, in these conditions, absorbs new knowledge, the phenomenon of "internalization" occurs (Shilanan, 2010: 53). The internalization is "when a person trying to adapt to environmental structures through integrating it with his own structures" (Haji Arbabi and Safarian Tusi, 2008: 38). This phenomenon has a kind of tension in which a person would be more vulnerable in the face of critical situations.

Prevalent intellectual tensions among this population are the conflict between traditions and familial beliefs and new environments with college friends, relationships with the opposite sex, concerns related to field of study and future employment (Bagheri, 2006) that causes stress and intense excitement in this population and provides a basis for cultural conflict, problems of personality and identity crises and may even lead to suicide, drug addiction, moral corruption and the like. While in some academic disciplines that are less welcomed, the students are less motivated because of the absence of career prospects and lack of sufficient knowledge of the field of study. Interestingly, disciplines which are less welcomed by the student, have a greater impact on the future of the country and their positive and negative effects are more extensive. So, the students in this field needs to identity construction. Physical space is one of the factors that affect the intensity in these cases, As far as some experts believe humans are affected by space, rather than affect it (Lotf Ata, 2008: 73). Synchronization phenomenon of "change and the formation of the identity of the person" at the age requirements and other various factors causing the crisis of identity and cultural problems that led many student community must be answered and suitable approach to be taken. On the other hand, research suggests that space and the built environment has a significant influence on the formation and structure of the intellectual and cultural identity and lifestyle and can result in the formation, intensification or reduction of issues that affect human social and psychological aspects (Mortazavi, 2001) (Pourhossein, 2011:27). However, the impact of physical space has been less used in response to these needs.

\section{METHODOLOGY}

The methodology used in any part of the research varies depending on the nature of each chapter. Library method and previous studies conducted at universities, university counseling centers and experts and deputy directors of cultural and university students were used in order to identify individual characteristics, personality and common cultural and psychological dimensions of the student community. Documentary and library method has been used to study the theory and history of studies. The method has been used to pathology of spaces in universities that should be placed in the descriptive - survey category. It is a survey, because researchers tried to interview experts in order to collect data and it is sectional, because the results may change over time. Comments of the experts in this field were collected in order to carry out the pathology of the status quo of university spaces, and the results were performed through content analysis. The experts and professors of 5 public universities, their technical managers and construction experts of the Ministry of Science, Research and Technology were used in order to achieve proper physical ideas on improving the social and cultural dimensions of space through body design and organizing educational space. Survey method among the students of the same five universities in Tehran has been used in order to evaluate the desirability of cultural spaces in universities in order to achieve the opinions of the interviewing and all this parts are cross-sectional analysis.

Research conducted in 10 universities where the pathology of physical spaces, surveys and interviews of experts and students will be carried out. Snowball method has been used in the selection of university professors. In this way, each expert should introduce another expert in this field and this process continues. Since this study was conducted using the best experts in the field, we interviewed 10 persons and review and summation were carried out through content analysis.

\section{THEORETICAL FOUNDATIONS}

Techniques to create satisfaction in educational facilities and user satisfaction with the educational environment leads to development of their talents and greater returns on educational centers (Mortazavi, 1997). About consent of space, we can say that architecture is effective in student satisfaction with educational centers. Techniques to create satisfaction in educational facilities include: 


\section{PHYSICAL COMFORT}

Satisfaction through specific physical parameters such as temperature, view, noise, location, number of rooms in the building will be measured. The qualitative aspects of the environment is considered as one of the parts of the human-environment relationship and satisfaction with environment (Rafieian and Khodaei, 2009).

\section{THE SENSE OF BELONGING TO SPACE}

The sense of belonging to the learning environment is the most important needs. One of the effective strategies to enhance students' sense of belonging to a learning environment is to use "pattern of school as home", which means that using elements of interior design to induce students feel at home (Kamelnia, 2010).

\section{ENVIRONMENTAL ATTRACTION}

Beauty and interior designs: User influence on the growing users is broad and seriously emphaised by the investigations. This poetic relationship is realized when we say that children need nutritious food, but these substances are not absorbed only through mouth, but also our senses can absorb all this materials required (Dey, 2007).

\section{ENVIRONMENTAL PERCEPTIONS}

Environmental perceptions is the basis of satisfaction with the quality of environment. Environmental perception is the process through which human chooses the required data based on the needs of environment (Motallebi, 2001: 56).

\section{PSYCHOLOGICAL SECURITY}

Hierarchies and defensible space have a supportive aspect. These two induce a sense of security, which leads to a feeling of safety and security that are vital in the age of growth (Dey, 2007).

\section{BODY AND PHYSICAL SPACE}

Physical elements create a sense of belonging through harmony and meet human needs in place. These elements are very important in the design of each of the variables of color, shape, texture, scale and type of organization based on human needs and providing the kind of activities in space. As an important part of the body of cities, views and urban housing should be designed, so that it can increase the sense of belonging in viewers (Motallebi and Foroozandeh, 2011).

\section{PHYSICAL BELONGING TO LOCATION}

This type of belonging derived from elements and components as part of the process of identifying the physical location and human identity. Richter and Lavarkas point to the important role of the physical belonging accordingly, a person remembers environment along with the physical elements in shaping the meaning of belonging (Javan Foroozandeh and Motallebi, 2011: 32).

\section{THE ROLE OF THE PHYSICAL ENVIRONMENT ON THE DYNAMICS OF EDUCATION}

In most countries, especially in our country, education was against the spirit of research and exploration. Rather than educate, the educational system tries to inform students from the outcome of other people's investigations. This quality is associated with the learning environment in the educational centers, not just educational program. Learning environment in educational institutions been created according to classical principles, inject information and data in minds and is not designed to search and discover new content. In adulthood, this laziness is observed with reluctance to research and investigations and training centers also believes that "understanding needs to hearing and learning is achieved by memorizing". In this environment, the basis of work is Training and there is no education in it. In this case, teacher absolutely obeys from the curriculum and the teacher is the main axis and students are quite impressed by the teacher. In the training process, talking and listening are combined and there is no search and discovery in this program and tools and facilities have not been provided for this purpose. In addition, other spaces such as corridors and courtyards of educational institutions do not have a fresh environment and in accordance with mood of users. According to modern ideas of psychology, the human mind naturally tends to searching and loves exploring even without external factors such as punishment and encouragement. Based on these 
findings, the human soul is full of questions and ambiguities by which he tirelessly tends to research and learning. On this basis, educational environment fits perfectly with the spirit and human nature and tries to guide the searcher power to the original meaning in anything. Thus, in an advanced learning environment, the researcher is responsible for training and he tries to guide them towards research, experience and testing with other classmates. This is the same phenomenon is known today as "student-centered learning environment" in which a person trained by the environment and with all its features, not only by the teacher. The first feature of this environment is to diversify factors and teaching methods, which provides vast possibilities to recruit tools and educational technologies. Science can be better understood through observation compared with descriptions and hear. The second feature is that training in this regard should be considered as a collective work and should be done through collaboration. In this case, social personality can grow through learning and he will be ready to participate in social activities. The third characteristic of this environment is that the research is important as much as the final result and research methodology and finding answers are also considered as an effective factor in mental development (Khosrowjerdi and Mahmoud, 2014).

\section{RESEARCH BACKGROUND \\ RESEARCH CONDUCTED WITHIN THE COUNTRY}

Mousavi (2015) conducted a study entitled "Spatial analysis of crime hotspots in the neighborhoods of Yazd city with an emphasis on cultural programming".

Mahdavinejad and Pourfathollah (2015) conducted a study in conjunction with the new lighting technologies and promote a sense of belonging of citizens in the urban body in Tehran.

Khosrowjerdiand Mahmoodi (2014) conducted a study entitled "School, a safe home to live and learn".

Dadres and Sharifi (2014) conducted a study on the establishment and evaluation of academic quality and the conditions for quality of higher education in Tehran University.

Mousa Kazemi et al (2013) examined the spatial performance in higher education institutions in the sustainable development of urban culture in the regions 3 and 19 of Tehran metropolis.

Jaydari and Jafarikhah (2013) examined the physical components of learning environments and their impact on user behavior.

Javadi Bora et al (2013) examined the factors that affect the quality of distance education (case study: the Graduate Center of Tehran PNU).

Azemati et al (2012) examined the environmental factors affecting students' satisfaction from educational spaces.

Davoudpour et al. (2011), in an article titled "improvement and renovation of old urban strategy towards achieving the physical dimensions of sustainable urban development (Case study: old texture in Sajadieh Alley)" examined the reform and renew this neighborhood through a new perspective and with a focus on sustainable development.

Bazargan (2007) in a study entitled "structuring for assessing the quality of higher education in Iran" came to the conclusion that one of the most important success factors in quality assurance in higher education is providing an adequate infrastructure to assess and improve the quality of higher education.

Rahnamaei (2004) in his book entitled "optimal distribution of universities and scientific centers through looking at the cultural geography of Iran "examined the spatial functions and cultural heritage in urban areas and provided a scientific solution to the spatial distribution pattern and their location.

\section{RESEARCH CONDUCTED OUTSIDE THE COUNTRY}


Paul et al (2013) conducted a study entitled "Crime prevention through environmental design in United Arabic Emirates".

Yupu et al (2012) in an article entitled "Sustainable development of cities in Heilongjiang Province based on the AHP method" Came to the conclusion that economic development and environmental quality are the most important indicators that are effective on sustainable urban development in this province.

Lewicka (2009) conducted a study entitled "place of attachment, place identity and location" and belonging to the location described as an extension of the 'I'.

Wiewel \& Perry (2008) writes in his book "World Universities and urban development": in recent years, research on the role of universities in the development of cities in the United States have been increased.

Dias and et al (2007), in Brazil, studied the role of spatial arrangement in the development of specific users' behaviors. Research results showed that the spatial and social factors contribute to the lack of security and increase crime, due to their effects on the environment and spatial components of urban open spaces.

\section{INFERENTIAL STATISTICS}

First hypothesis: It seems students who have high naturalism, believe that green space has a great impact on educational quality.

According to the table below, in the test conducted between two variables, there is a strong correlation between naturalism of students and attitude to improve the educational quality. Given the amount of $r$ $=406$, this is significant at the level of error of less than 0.01 because the obtained sig is less than 0.01 . So $\mathrm{p}<0.01$ and the hypothesis is confirmed, which means that there is a significant relationship between these two variables.

Table 1. Pearson correlation coefficient between naturalism and improve educational quality

\begin{tabular}{|l|l|l|l|}
\hline Variable & number of samples & $\begin{array}{l}\text { Correlation } \\
\text { Coefficient }\end{array}$ & naturalism \\
\hline $\begin{array}{l}\text { Attitudes towards } \\
\text { improve educational } \\
\text { quality }\end{array}$ & 450 & Pearson coefficient $r$ & 406. \\
\cline { 3 - 4 } & & Significance level & 000. \\
\hline
\end{tabular}

Second hypothesis: It seems that students whose attitudes to the spatial positions is associated with a high spatial coherence, believe that spatial coherence has a great impact on educational quality.

According to the table below, in the test conducted between two variables, there is a strong correlation between spatial coherence of students and attitude to improve the educational quality. Given the amount of $r=119$, this is significant at the level of error of less than 0.01 because the obtained sig is less than 0.01 . So $p<0.01$ and the hypothesis is confirmed, which means that there is a significant relationship between these two variables. This relationship is as follows: People who believe that the integrity of the environment is important, have a better attitude to improve the educational quality. This indicates that the cohesion has a positive and meaningful impact on the attitude to improve the educational quality.

Table 2. Pearson correlation coefficient between spatial coherence and improve educational quality

\begin{tabular}{|l|l|l|l|}
\hline Variable & number of samples & $\begin{array}{l}\text { Correlation } \\
\text { Coefficient }\end{array}$ & Spatial coherence \\
\hline $\begin{array}{l}\text { Attitudes towards } \\
\text { improve educational }\end{array}$ & 450 & Pearson coefficient $r$ & 119. \\
\cline { 3 - 4 } & & Significance level & 017. \\
\hline
\end{tabular}


quality

Third hypothesis: It seems that students who believe that spatial access is so important for individuals, believe that spatial access has a great impact on educational quality.

According to the table below, in the test conducted between two variables, there is a strong correlation between spatial access of students and attitude to improve the educational quality. Given the amount of $r=250$, this is significant at the level of error of less than 0.01 because the obtained sig is less than 0.01 . So $\mathrm{p}<0.01$ and the hypothesis is confirmed, which means that there is a significant relationship between these two variables.

Table 3. Pearson correlation coefficient between spatial access and improve educational quality

\begin{tabular}{|l|l|l|l|}
\hline Variable & number of samples & $\begin{array}{l}\text { Correlation } \\
\text { Coefficient }\end{array}$ & Spatial access \\
\hline $\begin{array}{l}\text { Attitudes towards } \\
\text { improve educational } \\
\text { quality }\end{array}$ & 450 & Pearson coefficient $\mathrm{r}$ & 250. \\
\cline { 3 - 4 } & Significance level & 000. \\
\hline
\end{tabular}

Forth hypothesis: It seems that students who have higher education, believe that education has a great impact on educational quality.

According to the table below, in the test conducted between two variables, there is a strong correlation between education and attitude to improve the educational quality. Given the amount of $r=260$, this is significant at the level of error of less than 0.01 because the obtained sig is less than 0.01 . So $p$ $<0.01$ and the hypothesis is confirmed, which means that there is a significant relationship between these two variables.

Table 4. Pearson correlation coefficient between education and improve educational quality

\begin{tabular}{|l|l|l|l|}
\hline Variable & number of samples & $\begin{array}{l}\text { Correlation } \\
\text { Coefficient }\end{array}$ & Education \\
\hline $\begin{array}{l}\text { Attitudes towards } \\
\text { improve educational } \\
\text { quality }\end{array}$ & 450 & Pearson coefficient $\mathrm{r}$ & 260. \\
\cline { 3 - 4 } & Significance level & 000. \\
\hline
\end{tabular}

Fifth hypothesis: It seems that students who are older, believe that age has a great impact on educational quality (the more the age, the more the educational quality).

According to the table below, in the test conducted between two variables, there isn't any strong correlation between age and attitude to improve the educational quality. Given the amount of $r=-$ 0.55 , this is not significant at the level of error of less than 0.01 because the obtained sig is more than 0.05 . So $p<0.01$ and the hypothesis is not confirmed, which means that there isn't any significant relationship between these two variables.

Table 5. Pearson correlation coefficient between age and improve educational quality

\begin{tabular}{|l|l|l|l|}
\hline Variable & number of samples & $\begin{array}{l}\text { Correlation } \\
\text { Coefficient }\end{array}$ & age \\
\hline $\begin{array}{l}\text { Attitudes towards } \\
\text { improve educational } \\
\text { quality }\end{array}$ & 450 & Pearson coefficient $r$ & 055. \\
\cline { 3 - 4 } & Significance level & 276. \\
\hline
\end{tabular}


Sixth hypothesis: There is a relationship between gender and attitude to improve the educational quality.

According to the table below, the value of $t$ is equal to -1.36 , which is significant at 0.174 , because sig is greater than 0.05 . The averages of two populations are different just a score. As a result, this hypothesis is not acceptable, which means that there isn't any significant relationship between gender and attitude towards improve educational quality with 0.95 confidence.

Table 6. T-test for two independent groups between gender and attitude towards improve educational quality

\begin{tabular}{|l|l|l|l|l|l|}
\hline Variable & Gender & Average & $\begin{array}{l}\text { Standard } \\
\text { deviation }\end{array}$ & T & Gender \\
\hline $\begin{array}{l}\text { Attitudes towards improve } \\
\text { educational quality }\end{array}$ & Male & 59.455 & 10.431 & 1.360 & 0.174 \\
\cline { 2 - 4 } & Female & 60.915 & 11.431 & & \\
\hline
\end{tabular}

Seventh hypothesis: There is a relationship between marital status and attitude to improve the educational quality.

According to the table below, the value of $t$ is equal to 2.83 , which is significant at 0.03 , because sig is greater than 0.05 . The averages of two populations are different. As a result, this hypothesis is acceptable, which means that there is a significant relationship between marital status and attitude towards improve educational quality with 0.95 confidence.

Table 7. T-test for two independent groups between marital status and attitude towards improve educational quality

\begin{tabular}{|l|l|l|l|l|l|}
\hline Variable & Gender & Average & $\begin{array}{l}\text { Standard } \\
\text { deviation }\end{array}$ & T & $\begin{array}{l}\text { Marital } \\
\text { status }\end{array}$ \\
\hline $\begin{array}{l}\text { Attitudes towards improve } \\
\text { educational quality }\end{array}$ & Male & 54.328 & 9.291 & 2.83 & 0.03 \\
\cline { 2 - 4 } & Female & 65.144 & 12.754 & & \\
\hline
\end{tabular}

Eighth hypothesis: There is a relationship between income status and attitude to improve the educational quality.

According to the table below, in the test conducted between two variables, there isn't any strong correlation between income status and attitude to improve the educational quality. Given the amount of $r=-0.68$, this is not significant at the level of error of less than 0.01 because the obtained sig is more than 0.05 . So $\mathrm{p}>0.01$ and the hypothesis is not confirmed, which means that there isn't any significant relationship between these two variables.

Table 8. Pearson correlation coefficient between age and improve educational quality

\begin{tabular}{|l|l|l|l|}
\hline Variable & number of samples & $\begin{array}{l}\text { Correlation } \\
\text { Coefficient }\end{array}$ & Income \\
\hline $\begin{array}{l}\text { Attitudes towards } \\
\text { improve educational } \\
\text { quality }\end{array}$ & 450 & Pearson coefficient $r$ & 068. \\
\cline { 2 - 4 } & Significance level & 125. \\
\hline
\end{tabular}

\section{REGRESSION ANALYSIS}

Independent variables such as age, education, income, naturalism, and spatial coherence space access and the independent variables which is attitude toward improve the educational quality were entered in a regression equation using concurrency manner. 
Then, the coefficients B, beta, standard error, the value of $\mathrm{T}$, significant sig and multiple regression will be shown for the independent variable of regression.

\section{MULTIPLE REGRESSION}

The first correlation is zero-order, which shows the correlation between the variables without the control variable. Below, the zero-order correlation for four variables of educational level, the amount of naturalism, spatial coherence and spatial access is high. But the amounts for other variables as age and income is low. Partial correlation $\mathbb{B}$ : it is a statistical correlation through which one or more variables can be controlled, that shows the correlation between dependent and independent variables after removing the correlation between the two variables with independent variables. As can be seen, the amount of the four variables of educational level, naturalism, spatial coherence and spatial access is high. But the amounts for other variables including age and income is low and variables of naturalism (.251) and spatial coherence (.408) compared to other variables, have the strongest correlation with the attitude to improve the educational quality. This has the highest effect in the beta coefficient of the regression with (.340) and (.544). Half-denotative correlation: this correlation is a statistical control through which one or more variables can be controlled (Sarmad, 2005). This index shows the linear correlation between the independent variable after excluding the effect of other independent variables on the dependent variable. The results of this correlation for four variables of educational level (-.104), naturalism (.184), spatial coherence (.369) and spatial access (.130) is high and the variables of age (-.086) and the amount of income (.029) are low level. But this correlation because it eliminates the linear effect of independent variables on each other, so the correlation is less than the two previous relationship. The important thing in these correlations is their amount for independent variables and its amount in the two zero-order correlation of the partial and halfdenotative for the independent variables affects the attitude to improve the educational quality. If so, then we explain the real relationship of these variables in the regression:

The regression results is as follows: The impact of independent variables on the dependent variable is shown using coefficients B. And beta coefficient standardized regression coefficient of each independent variable on the dependent variable and specifies the relative contribution of each independent variable in the model. These factors show that the impact of the four variables "education, naturalism, and spatial coherence and spatial access" is significant on the attitude to improve the educational quality with error less than $0.05 \%$ and $95 \%$ confidence.

Table 9 shows the summary of regression model analysis. As can be seen, $\mathrm{R}$ is equal to 0.615 and shows that there is a good correlation. $F$ value is significant in the values smaller than the error level of 0.01 . And it can be concluded that research regression model consisting of six independent variables is a good model and independent variables explained $33 \%$ of variance in attitudes to improve educational quality $(r=.24)$, that is a good amount of variance estimate for the attitude to improve the educational quality.

Table 9. Coefficients B, $\mathrm{T}$ and correlation for independent variables affecting improvement of educational quality

\begin{tabular}{|l|l|l|l|l|l|l|l|l|}
\hline $\begin{array}{l}\text { Independent } \\
\text { variables }\end{array}$ & B & S.E & Beta & T & Sig. & $\begin{array}{l}\text { Zero order } \\
\text { correlation }\end{array}$ & $\begin{array}{l}\text { Partial } \\
\text { correlation }\end{array}$ & $\begin{array}{l}\text { Half- } \\
\text { denotative } \\
\text { correlation }\end{array}$ \\
\hline education & 303. & 147. & 096. & 3.160 & 030. & 119. & 104. & 091. \\
\hline naturalism & 340. & 092. & 229. & 4.686 & 000. & 251. & 184. & 164. \\
\hline \multicolumn{1}{|l}{ Income } & 054. & 094. & 035. & 578. & 564. & 193. & 029. & 026. \\
\hline Age & 902. & 527. & 079. & 1.710 & 088. & 037. & 086. & 076. \\
\hline $\begin{array}{l}\text { Spatial } \\
\text { coherence }\end{array}$ & 544. & 070. & 355. & 7.815 & 000. & 408. & 369. & 374. \\
\hline $\begin{array}{l}\text { Spatial } \\
\text { access }\end{array}$ & 123. & 048. & 125. & 3.575 & 010. & 037. & 130. & 114. \\
\hline
\end{tabular}


Table 10. Summary of the regression model

\begin{tabular}{|l|l|l|l|l|}
\hline Model & R & Adjusted R2 & F value & Significance level \\
\hline Regression & 615. & 33. & 17.944 & 0.000 \\
\hline
\end{tabular}

According to the regression model, educational level with the level of error less than $.05 \%$, the power of $t(-3.360)$, beta coefficient (-.303) and with $95 \%$ confidence, there is a positive correlation with the attitude to improve the educational quality. According to this table, the spatial coherence (.355) has the greatest impact on attitudes to population policies. After that, there is naturalism (with beta coefficient, 340 that this amount of beta coefficient indicates that the per unit change in the naturalism variable, there would be a change in the attitude to improve the educational quality as much as 220 units).

So, we can say that spatial requirements include in these dimensions that have a positive effect on the attitude to improve the educational quality. When the dimensions be explained by individuals, the role of the attitude to improve the educational quality should be considered and this is affecting this attitude. So it is very important to consider the physical space of education and the educational quality. Spatial arrangement, location, exact settings and spaces in the learning environment are very important.

The age variable in the regression model with a significance level of 0.088 and the error level of $0.05 \%$ is not significant. In other words, the variable of age has no significant effect. But we saw in the correlation test that there is no significant relationship between age and attitude to improve the educational quality and this became insignificant after controlling the variables in the regression. In addition, the relationship between income and attitude to improve educational quality is not significant and it is more than the error level of $0.05 \%$.

\section{ANSWERS TO QUESTIONS}

- What are the shared individual, personal and cultural features in the student community?

This group has specific characteristics such as individual identity and social concerns, conflict between different cultures and thoughts, anxiety and worry (being away from family, career prospects, family independence, marriage), diversity, idealism and expressing dissatisfaction (different approaches to the concept of justice), lack of knowledge about the field of study and sometimes lack of interest in the discipline, emotional maturity, sexuality, etc. Below, personality of students can be seen that have been obtained through the NEO questionnaire and extraversion has the maximum amount (the dimensions of personality: introversion, extroversion, openness to experience, openness, and conscientiousness).

In addition, the following results were obtained through distributions the questionnaires among teachers and experts:

The student community is young and this feature makes the personality characteristics and cultural influences and educational space must be able to respond to this need. Prevalent intellectual tensions among this population are the conflict between traditions and familial beliefs and new environments with college friends, relationships with the opposite sex, concerns related to field of study and future employment that causes stress and intense excitement in this population and provides a basis for cultural conflict, problems of personality and identity crises and may even lead to suicide, drug addiction, moral corruption and the like.

- Considering the present situation of spaces in universities, what are the performance and culture conflicts that students faced with them?

For this purpose, this issue was investigated by a questionnaire. Thus, we can conclude that there is a conflict between the present situation at universities and cultural perspectives. 
- Are you able to provide a physical approach in giving identity to the spaces?

Location is one of the important part of people's identity. For a young student also has the function of identity and the physical spaces are also important for students. Elements related to identity are different for students. Thus, pay attention to the architecture of the university environments is very important in students' satisfaction or dissatisfaction. The first thing that catches the attention of a student is the physical changes in the learning environment. So, this place should have the signs associated with an academic environment. For example, universities should have different spaces for talking and conversation. In the other words, there should be possibility of dialogue in different groups. The authorities should also pay attention to creativity and spatial variation.

- What are the physical solutions in improving relations between human and environment on university campuses?

As mentioned above, university is not just an ordinary place. The concept of the university is various factors and events that are caused by human actors. There is a dialectical relationship between human being and the environment in which he lives. If this provide a more relaxed environment, these relationships will improve. Small and crowded environment can lead to anxiety and destroys the focus of students. Other effective strategies are paying attention to the psychological aspects of environmental design, adequate space for walking, taking into account the specific areas of cultural and artistic activities in the area and the use of interactive design in spaces.

- In terms of students, which problems should be addressed to enhance the educational quality and improve social interactions?

Students believe that green space, pleasant environment, cohesion, environment, access to the space environment are important priorities in order to improve the satisfaction of learning and improve social interactions. Independent variables such as age, education, income, naturalism, and spatial coherence space access were evaluated with dependent variable which was attitude to improve the educational quality. The amount of the four variables of educational level, naturalism, spatial coherence and spatial access is high. But the amounts for other variables including age and income is low.

- What are the experts' ideas on improving the space in universities with an emphasis on social and cultural issues?

According to the results obtained from professors and experts, we can say that policymaking at the macro level in relation to the cultural policy based on cultural principles and culture of students, compliance of spaces in universities with traditional and modern culture, creating spaces with Iranian and Islamic identity and create spaces for security, safety and welfare of students are the most influential ideas on improving physical space in order to improve students' cultural and social issues.

\section{CONCLUSION}

- There is a strong correlation between naturalism of students and attitude to improve the educational quality.

- There is a strong correlation between spatial coherence of students and attitude to improve the educational quality.

- There is a strong correlation between spatial access of students and attitude to improve the educational quality.

- There is a strong correlation between education and attitude to improve the educational quality.

- There isn't any strong correlation between age and attitude to improve the educational quality. 
- There isn't any relationship between gender and attitude to improve the educational quality.

- There is a relationship between marital status and attitude to improve the educational quality.

-There isn't any relationship between income status and attitude to improve the educational quality.

- The first correlation is zero-order, which shows the correlation between the variables without the control variable. Below, the zero-order correlation for four variables of educational level, the amount of naturalism, spatial coherence and spatial access is high. But the amounts for other variables as age and income is low. Partial correlation $\mathbb{R}$ : it is a statistical correlation through which one or more variables can be controlled, that shows the correlation between dependent and independent variables after removing the correlation between the two variables with independent variables. As can be seen, the amount of the four variables of educational level, naturalism, spatial coherence and spatial access is high. But the amounts for other variables including age and income is low and variables of naturalism (.251) and spatial coherence (.408) compared to other variables, have the strongest correlation with the attitude to improve the educational quality. This has the highest effect in the beta coefficient of the regression with (.340) and (.544). Half-denotative correlation: this correlation is a statistical control through which one or more variables can be controlled (Sarmad, 2005). This index shows the linear correlation between the independent variable after excluding the effect of other independent variables on the dependent variable. The results of this correlation for four variables of educational level (-.104), naturalism (.184), spatial coherence (.369) and spatial access (.130) is high and the variables of age (-.086) and the amount of income (.029) are low level. But this correlation because it eliminates the linear effect of independent variables on each other, so the correlation is less than the two previous relationship. The important thing in these correlations is their amount for independent variables and its amount in the two zero-order correlation of the partial and halfdenotative for the independent variables affects the attitude to improve the educational quality. If so, then we explain the real relationship of these variables in the regression:

- The regression results is as follows: The impact of independent variables on the dependent variable is shown using coefficients B. And beta coefficient standardized regression coefficient of each independent variable on the dependent variable and specifies the relative contribution of each independent variable in the model. These factors show that the impact of the four variables "education, naturalism, and spatial coherence and spatial access" is significant on the attitude to improve the educational quality with error less than $0.05 \%$ and $95 \%$ confidence.

- In the summary of regression model analysis, $\mathrm{R}$ is equal to 0.615 and shows that there is a good correlation. $\mathrm{F}$ value is significant in the values smaller than the error level of 0.01 . And it can be concluded that research regression model consisting of six independent variables is a good model and independent variables explained $33 \%$ of variance in attitudes to improve educational quality $(\mathrm{r}=$ .24), that is a good amount of variance estimate for the attitude to improve the educational quality.

- According to the regression model, educational level with the level of error less than $.05 \%$, the power of $t(-3.360)$, beta coefficient (-.303) and with $95 \%$ confidence, there is a positive correlation with the attitude to improve the educational quality. According to this table, the spatial coherence (.355) has the greatest impact on attitudes to population policies. After that, there is naturalism (with beta coefficient, 340 that this amount of beta coefficient indicates that the per unit change in the naturalism variable, there would be a change in the attitude to improve the educational quality as much as 220 units).

- So, we can say that spatial requirements include in these dimensions that have a positive effect on the attitude to improve the educational quality. When the dimensions be explained by individuals, the role of the attitude to improve the educational quality should be considered and this is affecting this attitude. So it is very important to consider the physical space of education and the educational quality. Spatial arrangement, location, exact settings and spaces in the learning environment are very important. 
- The age variable in the regression model with a significance level of 0.088 and the error level of $0.05 \%$ is not significant. In other words, the variable of age has no significant effect. But we saw in the correlation test that there is no significant relationship between age and attitude to improve the educational quality and this became insignificant after controlling the variables in the regression. In addition, the relationship between income and attitude to improve educational quality is not significant and it is more than the error level of $0.05 \%$.

- There is a conflict between the present situation at universities and cultural perspectives.

\section{GUIDELINES AND RECOMMENDATIONS}

According to the analysis made by the Delphi Group, the following recommendations be presented:

The most important solutions related to the physical environment in the academic spaces are as follows:

1. Naturalism which contains the following items:

- Creating landscapes in educational spaces.

- Creating green spaces designed according to the indigenous principles and standards of educational facilities.

- Designing spaces should be able to induce psychological security.

2. Spatial coherence which contains the following items:

- Suitable location for salons and sports stadiums in educational environments

- Pay attention to Iranian-Islamic culture and identity.

- Creating spaces based on traditional and modern culture

- Creating open educable

- Creating spaces for security, safety and welfare of students

- Creating innovative and dynamic learning environment

- Designing physical spaces based on local culture

- Using color psychology in coloring educational environments

3. Spatial access which contains the following items:

- Designing and building of certain and appropriate signs for access to different learning environments

- $\quad$ Access to elevators and toilets on the floors of buildings and public places

- Creating the appropriate equipment, such as car parks, taxicabs and special places to improve social interactions

- $\quad$ Ease of movement and access to education and technology

- In addition to students, the physical design must be suitable for all citizens.

\section{REFERENCES}

Bagheri, A., (2006), Understanding the motivation of students to turn to drugs, research projects Pourhossein, R., (2011), measuring the sense of identity and place in Hashtgerd New City compared to Hashtgerd Old City, master's thesis, Supervisor: Seyed Mehdi Mousa Kazemi, Tehran, Payam Noor University

Haji Arbabi, F, Safarian Tusi, M. (2008), "Comparison of Cognitive theorists: Piaget and Vygotsky" Practice, Mashhad.

Shilanan, N. (2010), Jean Piaget and Vygotsky's ideas in terms of constructivism approach and its implications in education, master's thesis, Supervisor: Tayebeh Mahroozadeh, Al-Zahra University.

Qobadian, V., (2005), the principles and concepts of contemporary architecture in the West, Office of Cultural Research publications 
Mortazavi, Sh., (2001), Environmental Psychology and its application, Publications Center of martyr Beheshti University, Tehran.

Motallebi, G., (2001) new knowledge of environmental psychology at the service of architecture and urban design, fine arts journal, the tenth period- Winter, Tehran University.

Mir Najaf Mousavi, 2015, Analysis of the hot spots in the neighborhoods of Yazd with an emphasis on cultural programming, article 4, Volume 47, Issue 2, Summer 2015, p. 233

Loft Ata, A., the impact of environmental factors on learning and behavior in learning environments (elementary) in the city, urban management, Autumn, 2008, No. 21, p. 7390

Mortazavi, Sh., 1997 educational spaces from the perspective of environmental psychology, Organization of renovation of schools, Bureau of Investigation and Research.

Seyed Mahdi Mousa Kazemi, Mohammad Taghi Rahnamaei, Mohsen Golpaygani, 2013, to examine the spatial performance of higher education institutions in the sustainable development of urban culture in Tehran (Case Study: District 3 and 19), studies of urban planning, first year second edition, summer, 2013, pp. 11-27

Mohammad Ali Javadi Bora, Hossein Najafi, Mehran Farajollahi, factors affecting the quality of distance education (case study: the Graduate Center of Payam-noor University of Tehran), Summer, courses 92, 4 (2), Faculty of Education, University of educators, Sari, Iran

Arghavan Jaydari, architecture, Islamic Azad University of Hamedan, physical examination of the educational environment and its impact on user behavior, Islamic Azad University of Hamedan, National Conference on Human-oriented architecture and urban planning (2013)

Mahdavinejad, M., Pourfathollah M., new technologies to improve lighting and sense of belonging of citizens (Case study: Tehran municipal bodies), Human Geography Research (Geographical Research): Spring 2015, Volume 47, Number 1; from page 131 to page 141.

Azemati, H., Sabahi, S., Azemati, S., (2012). Environmental factors affecting students' satisfaction from educational spaces. Naqsh-e Jahan, second year, No. 2, Pp. 31- 42

Rafieian, M., Khodaei, Z., (2009). Check indicators and criteria for citizen satisfaction with urban public spaces.

Kamelnia, H., Eslami, G., Hanachi, P., (2010). Analysis and evaluation based on the collective architectural characteristics of the collective feeling.

Khosrowjerdi, N., Mohammadi, M., (2014). School, a safe home for life and living, the ninth symposium on Advances in science and technology, Mashhad, 29 November, 2014.

Sarmad, Z., Bazargan, A., (2005). Research methods in the behavioral sciences, Agah Publications, Tehran.

Javan Forouzande, A., Motallebi, G. (2011). The concept of sense of belonging to place, and its formations. Number eight, the fifth year, spring and summer of 2011. p. 37-27.

Day, C. (2007), Environment \& children: passive lessons from the everyday environment, Uk: Elsevier Architectural press.

Harvey, David, 1996, justice, Naturre \& the geography of Difference, Blackwell 